\title{
The Influence of Chinese Culture on Learning Chinese as a Second Language: A Case Study of Zimbabwean Students Learning Chinese as a Second Language
}

\author{
Godfrey Chisoni \\ Faculty of Arts, Jilin University of China, Jilin, China
}

\section{Email address:}

gchisoni@yahoo.com

To cite this article:

Godfrey Chisoni. The Influence of Chinese Culture on Learning Chinese as a Second Language: A Case Study of Zimbabwean Students Learning Chinese as a Second Language. International Journal of Language and Linguistics. Vol. 3, No. 2, 2015, pp. 33-39. doi: $10.11648 /$ j.ijl1.20150302.11

\begin{abstract}
Learning Chinese as a second language is a hot and rising issue all around the world. Although the teaching and learning of Chinese as a second language is getting a lot of support from the Chinese government, through the establishment of Confucius Institutes which are aimed at the spreading and the promotion of Chinese language and culture. The spreading of Chinese language and culture is still facing a lot of challenges due to cultural differences. If the teaching and learning of Chinese language is to going develop, there is need to establish new teaching frameworks, teaching methods and approaches which can accommodate and promote culture learning in the Chinese language classes. This paper is aimed at exploring the importance of culture in second language learning, drawing examples from the teaching and learning of Chinese language and culture in Zimbabwe. Language and culture are inseparable, language is the carrier of culture and a mirror to reflect the culture. It is through language that culture is passed from the generation to generation. Without culture, language is like a tree without roots, it cannot stand, the same is with culture without language, It cannot survive. In second language learning and teaching it is important for the language teachers to understand the culture of the students and it's more important for the students to understand the culture of their target language. Chinese language is rich with culture, the expressions, grammar, characters, idioms and everything in Chinese language has a cultural connotation and meaning which if not taught well, it brings misunderstandings and a lot of problems. New teaching frameworks and approaches should be established basing on the differences that exist between the two cultures.
\end{abstract}

Keywords: Chinese Culture, Second Language Acquisition, Zimbabwean Culture

\section{Introduction}

The learning of Chinese in the contemporary world has become a global trend. The demand for learning Chinese was triggered by the political, social and economic demands. The world over people have seen the necessity of learning and understanding Chinese culture. According to the (The People's Daily ,2006) there is more than 40 million foreigners learning Chinese the world over and the number is still rising very fast. The Chinese government has been in constant support to the learning and support of Chinese as a second language, by so, they have established Confucius Institutes the world over to support the spreading of Chinese language and culture. According to Jeffrey Gil (2008) there is little doubt that China sees the promotion of Chinese language learning as one of its soft power tools...teaching
Chinese as a foreign language is an integral part of China's reform and opening up drive... to enhance the friendship and mutual understanding as well as the economic and cultural cooperation and exchanges between China and other countries around the world.

In Africa, the rapid increase of Chinese investments and trade, as China is currently Africa's biggest trading partner has spurred the trend of learning Chinese language. According to Zhang Chun (2014) China's economic ascent and the increasing engagement between China and Africa are the two main forces increasing the need for Africans to understand Chinese language. The relationship between China and Zimbabwe is recorded to have started some 600 years ago between the Ming dynasty of China and the 
Mhunhumutapa ${ }^{1}$ Empire in Zimbabwe were they used to do barter trade and cultural exchange. The contemporary interactions and relations between China and Zimbabwe were cemented in the 1960s when Chinese government gave military support to the Zimbabwean second Chimurenga ${ }^{2}$ war against the British colonial rule. The two countries enjoys a strong bilateral relationship, in the year 2003 the Zimbabwean government even introduced the "Look East Policy" to give priority to investors from China, Iran, Japan, Singapore and many other Asian countries.

Due to the strong relationship shared by the two countries, the two governments have worked hard in promoting the Chinese language so that both parties can do business together without language barrier and reduce suspicion. In doing so the Chinese government has established some Chinese language learning centers in Zimbabwe. Most Zimbabweans use English as their formal language and local languages which include Shona which is a Bantu language spoken by $76 \%$ of the Zimbabwean people and Ndebele which is spoken by $18 \%$ of the Zimbabwean people. The Zimbabwean culture is greatly influenced by the Western culture and Christianity. Most Zimbabweans learning Chinese language are adults who have never experienced Chinese culture and have different perspectives about Chinese culture. Although there have been a lot of support from various institutions to the learning of Chinese in Zimbabwe a lot of Zimbabwean students think and consider Chinese language as very difficult to study and master. This is because Chinese language has the writing system which is different to the Zimbabwean way of writing and also that Chinese language is very close to the Chinese culture, to understand Chinese language there is also need to understand the Chinese culture.

Language and culture are interdependent, you cannot talk of language without culture, language and culture are intertwined, and it is through language that a community or people can express their views and can communicate and pass on culture from generation to generation. According to Edward Sapir (1884-1939) language is an anonymous, collective and unconscious art, the result of the creative of thousands of generations. This shows how language and culture are inseparable. Yang Zhong (2010:114) " it is common sense that language is the principal means by which our social lives are conducted ...language as a product of man's social life is part of culture and the principal means by which culture is passed on from generation to generation . Culture is important to language, it is also important to the second language learning.

Zimbabwe's culture is different from the Chinese culture.

1The Kingdom of Mutapa, sometimes referred to as the Mutapa Empire (Shona: Wene we Mutapa; Portuguese: Monomotapa) was a Shona kingdom which stretched between the Zambezi and Limpopo rivers of southern Africa in the modern states of Zimbabwe and Mozambique.

2 Chimurenga is a Shona language word for liberation, which entered common usage during the Rhodesian Bush War. The word's modern interpretation has been extended to describe a struggle for human rights, political dignity and social justice.http//:www.zimbabwenews.co.zw
The Zimbabwean culture is greatly influenced by Christianity whilst Chinese culture is mainly influenced by the ideologies derived from Confucianism and Taoism, when Zimbabwean students start to learn Chinese language, a lot of misunderstandings are brought to the classroom which is hindering the development and progression of Chinese language learning in Zimbabwe.

\section{Background}

\subsection{Chinese as a Second Language}

Chinese as a second language is a study of Chinese language (Mandarin) by non-native speakers of the language. According to Liu Xun (2002) Chinese as second language was already there as early as the 16 th Century when some European missionaries used to come to China and were believed to have mastered the language without help from any grammatical books. Many people have been learning Chinese in the past for different reasons, for example in Zimbabwe during Zimbabwe's second Chimurenga war against the British colonial rule when Zimbabwe's military cadres used to go and be trained in China. The 21 st Century saw the rise in learning Chinese as a second language as the Chinese economy rose very fast and Chinese government was engaged in a lot of activities the world over. Around the year 2000 China introduced the FOCAC ${ }^{3}$ (Forum on ChinaAfrica Co-operation) to cement and expand its political and economic ties with African countries (Zhang Chun 2014:8). This development amongst many other developments has increased the necessity to learn Chinese by Africans. The Chinese government has been deliberate in the promotion of Chinese as second language and culture as the need for learning Chinese was increasing the world over. To show their support on the promotion of Chinese language learning, the Chinese Ministry of Education aided by establishing Confucius Institutes the world over which are responsible for the promotion and spreading of Chinese language and culture.

\subsection{The Relationship between Language and Culture}

Culture was first defined in the book The primitive by a British scholar Edward Taylor in 1897 as "Culture... is that complex whole which includes knowledge, beliefs, arts, morals, law, custom and any other capacities and habits acquired by man as a member of society". Later scholars like Clifford Geertz defined culture as being characterized by certain facts, like it has to be shared by a community and not by an individual, and also as a symbolic meaning system in which language is one of the most important ones. Later scholars have different opinions on the definitions of culture, some even suggested that culture is influenced by the environment as it is man-made.

Language has many definitions, scholars have argued the definition of language and combining their thoughts,

3FOCAC(Forum on China- Africa Co-operation is an official forum between the People's Republic of China and the states in Africa 
language can be defined as the system of communication with codes and symbols and is used by humans to store retrieve, pass, organize and structure information. Language is used to maintain one's own and to acquire new culture. The relationship between culture and language is so strong and inseparable as it is seen in the above definitions .If learners of a new language are not given much information or don't learn the culture of the target language, it creates a lot of misunderstandings which may lead to suspicion or arguments, as it is quoted that one Turkish visitor who once visited the US and refused to eat hot dog as it is against his culture to eat dog meat. According to Li Sun(2013) Language is the primary vehicle by which a culture transmits its beliefs, values and norms... culture is the basis and one of the most important attributes of language and exerts great influence on the latter. If there is no culture, language will be like water without a source or a tree without roots. According to Krech (1962)" Children learning their native language are learning their own culture; learning a second language also involves learning a second culture to varying degrees.

In second language learning, culture also plays a very big role as different people from different cultures have different ways of learning, different ways of expressing themselves and different ways of relating to certain issues. During cultural transfer when learners are learning new language and new culture it is important for them to find ways to master the culture of the target language as it will influence their way of learning and acquiring the target language. According to Li Sun (2013) As a matter of fact, the most difficult thing for the language learners to deal with in their study of foreign language is not the linguistic forms or grammar, but the cultural difference. This is because most second language learners have already mastered another language and culture which will make it a bit difficult to understand the new culture of the target language.

\subsection{Learning Chinese as a Second Language in Zimbabwe}

Learning of Chinese in began in the 1960s and 1970s. During this period, Zimbabwe was fighting colonialism from the British people and received assistance from the Chinese government. The Zimbabwean soldiers would go to China to be trained and at this period that's when Zimbabweans started learning Chinese. Though learning of Chinese language in Zimbabwe dates back to the 1960s, the contemporary Chinese learning began in the years 2000, when Zimbabwe was experiencing a bad relation with the western countries and the government of Zimbabwe introduced the "look east policy" which was aimed at encouraging and giving priority to Asian investors to come and invest in Zimbabwe.

The introduction of the "look east policy" and the introduction of the FOCAC (Forum on China -Africa Cooperation) strengthened the already existent ZimbabweChina relationship raised the need for Zimbabwean people to learn some basic Chinese so that they can be able to communicate with Chinese people during meetings. The Chinese government has been deliberate in the promotion and expansion of Chinese language in Zimbabwe and the world over. In 2007 a Confucius institute was established at the University of Zimbabwe, this was in order to promote, expand and deliver Chinese language learning and teaching to the Zimbabweans who wanted to learn Chinese language. According to the Xinhua News Agency, in the year 2007 only 30 students were registered to study Chinese at the University of Zimbabwe Confucius Institute and by the end of 2013, more than 3000 students have been enrolled and studied Chinese at the university of Zimbabwe Confucius institute. In the short period that Zimbabwe has been offering Chinese lessons to the Zimbabwean students through the Confucius institutes and other learning institutions, a lot of development has been noted. In the year 2013 Zimbabwe was the leading African country to produce Chinese local teachers trained in China and with masters' degrees to teach Chinese.

Amongst the developments of teaching Chinese in Zimbabwe, Chinese language is now offered even at the primary school level and secondary school. The Churchill boys' high school located in the capital Harare has been offering Chinese lessons and its students have been successful in attending the international Chinese bridge and managed to get scholarships to study in China. Although learning Chinese has seen some developments, a lot of students still think Chinese language is very difficult to master. Chinese language is comprised of tones, characters, and this has brought many difficulties in mastering the language. Chinese language has a history of more than 5000 years. The writing system of Chinese language which can be traced back to the oracle bones of the Shang dynasty (1600BC-1046BC) shows the rich culture and history that the Chinese culture and language have. For students to fully understand the Chinese language students also need to understand Chinese culture as the Chinese language is closely linked to the Chinese culture.

The expanding in the learning and teaching of Chinese language has brought its challenges, a pilot research that has been done shows that most Zimbabwean students and teachers are not aware of the importance of culture in second language acquisition. The teaching approaches that are being used does not cater for the difficulties which are brought by the cultural differences. Although Chinese characters are regarded by many as the most difficult aspect in acquiring Chinese language, in Zimbabwe most students can write Chinese characters well although with some challenges. This was a result of tremendous efforts from the students and teachers to find learning strategies which make it easier for learning Chinese characters. The students have a good command in Chinese grammar and character writing, but they are incompetent in actual communication as they lack the cultural aspect of the language which enables them to communicate and express themselves in the target language.

\section{Brief Literature Review}

Previous researches on Chinese as a second language 
overemphasized the challenges and difficultness of Chinese characters, tones and the importance of grasping the Chinese grammar. Very little emphasis has been put on how cultural differences in second language learning can affect the way a foreign or second language is taught or learnt. For instance the majority of linguists in and out of China seem to agree that the major factor that makes Chinese language more difficulty to grasp is the complex writing system (Everson 1998; Shi\& Wan 1988; Walker 1989). Although Chinese characters are difficult to acquire, but the notion that they are the most difficult and should be given all the attention is affecting the growth and development of Chinese language, both to teachers and the students.

Chinese language and culture and language are inseparable, it is important for Chinese language teachers, linguists and researchers to pay attention to how cultural difference is affecting the growth and development of Chinese as a second language. According to Koda (2004) learning Chinese as a second language requires different types of metalinguistic and sociolinguistics than English. It is important that language researchers and teachers find new teaching approaches which accommodate culture in language learning. Scholars like Byram have advocated that in foreign language education has four components which are important and should be taken care of, namely language learning, language awareness, culture awareness and cultural experience. Byram believes that for second language to take place and to be successful an integrative approach should be provided for language learning and culture learning.

Since Chinese language was introduced in Zimbabwe at the Confucius institute very little research has been done on the ways and how Chinese culture can affect and is affecting the acquisition of Chinese language learning. Considering that Zimbabweans who are learning Chinese language are already adults who have already mastered their mother language and culture, in learning a second language there is sure influence coming from the mother language. Learning Chinese language in Zimbabwe is considered very hard, with the lack of Chinese culture, a lot of students fail to communicate in Chinese as they only master grammar and characters without much attention to the cultural aspect which should make them able to communicate well.

This paper doesn't totally agree that learning Chinese language is very difficult, though it's difficult but the learning strategies and the engagement of culture in the classes and the teaching approaches and techniques are the ones playing a big role in the acquisition of Chinese language in Zimbabwe. The paper argues that overemphasizing the difficultness of Chinese characters, tones grammar and other aspects and ignoring the Importance of culture in the learning of Chinese language is only perpetuating the challenges of learning Chinese. The argument is that Chinese language is comprised and is contained in the Chinese culture, the only way to improve the learning of Chinese language is to find new frameworks and teaching approaches which include culture learning, and culture learning in second language should be a priority.

\section{Research Questions and Aims}

The aim of the research is to find the key differences between Zimbabwean culture and Chinese culture which are affecting the growth of Chinese learning in Zimbabwe. Also it aims at exploring the current approaches to the teaching and learning of Chinese language in Zimbabwe with particular to culture.

The main research question is how and what approaches are being used in learning and teaching of Chinese language in Zimbabwe?

Also the research will explore how culture is constructed in teaching and learning of Chinese as a second language in Zimbabwe.

\section{Methodology}

The paper reports the results that were obtained from a pilot research that was done at the University of Zimbabwe Confucius Institute by attending classes and participating in the class in order to obtain firsthand information about the current situation in the teaching and learning of Chinese in Zimbabwe.

Interviews, observations questionnaires and desk research were used to obtain the information on the current teaching of Chinese in Zimbabwe and the extent to which people know about the value of Chinese culture in Chinese language.

The interviews were conducted through Skype, face to face interviews and some using WeChat according to the availability and convenience of the interviewees. The interviews done on Skype were done through texts messages and the interviews were done to both native Chinese language teachers in Zimbabwe and the local Chinese teachers.

\section{Key Findings and DISCUSSION}

The research which was done through Skype, face to face interviews and through the observations shows that although Zimbabwean students are able to acquire a lot of words, and grammar they are not able to construct sentences or to communicate as they are not aware of the importance of culture. According to Baker (2011a:62) "L2 users need to understand L2 communication as a cultural process and to be aware of their own culturally based communicative behavior and that of others.' The pilot research which was done in the schools in Zimbabwe offering Chinese language showed that Chinese language is expanding very fast and this has increased and perpetuated the challenges brought by this 'new language'. Although there are classes specifically programmed for Chinese culture, students still find it difficult to master the culture and they don't actually understand the importance of cultural awareness. 


\section{Major Issues Perpetuating the Challenges}

\subsection{The Schedule and Arrangement of Classes}

The interviewees complained about the schedule and the arrangements of the Chinese classes. The Confucius Institute at the University of Zimbabwe is affiliated to the Modern Languages department. This therefore allows Chinese language to be treated the same time as the other foreign languages being offered. The understanding of Chinese language is very limited leading to people treating Chinese language as other foreign language. Chinese language is very different from other foreign languages, it requires a lot of effort from both parties and it needs enough time because of its complex nature. During teaching of Chinese, a lot of Chinese language words have some cultural meanings which requires them to be explained adding some cultural content, Chinese language in Zimbabwe is treated as any other language. The time for the learning of the learning is very limited with only four hours per week for the language, and two hours per week for the culture course, this time is not enough and they should not regard Chinese as other foreign languages.

Most of the teachers are native Chinese teachers who have not stayed in Zimbabwe for a long time. The teachers do not actually understand Zimbabwean culture and through the interviews contacted, a lot of students lost interest in the learning of Chinese due to the teaching approaches being applied in the classroom. Zimbabweans generally are not time conscious, for example if a meeting is supposed to be at $2 \mathrm{pm}$, at least people should be notified that it should be there at $1.45 \mathrm{pm}$. Zimbabweans are usually late whilst Chinese people are very time conscious .This as simple as it might seem has led to a lot of problems as usually Chinese people don't understand this and end up applying harsh punishment to students like dismissing them from class amongst other things, and making the learning of Chinese and teaching less interesting.

\subsection{Textbooks for Learning Chinese and Culture}

The Chinese classes which are offered in different schools around Zimbabwe, usually they use the same system. The classes are divided as Chinese for beginners 1, 2 and 3. In Chinese for beginners 1 as the same with others, students are required to take two compulsory courses one for Chinese language and the other of Chinese culture and civilization. The text books used varies with the grade or the level of Chinese or learning. After learning for one year one can move from Chinese for beginners' level 1 to Chinese for beginners' level 2 and the same to level 3. Every level they have six hours per week for Chinese classes, which are divided as four hours of Chinese language and two hours of Chinese culture and civilization. The textbooks used are all from China. Everything in the book was set in China, for Zimbabwean students sometimes they don't understand the example or the context given in the book. At the University of Zimbabwe Confucius Institute, they use the textbooks 'Learn Chinese with me' (跟我学汉语) and the other one called 'New Practical Chinese' these books were all published in China, there setting, examples and everything is based in China, due to the shortage of time, students are not fully taught to understand as the passages and everything in the textbooks has a lot of cultural meanings which needs to be explained. It's difficult to explain some of the things in the books as they are Chinese things and in Zimbabwe they have never seen. There is a passage in the New Practical Chinese book 2, the passage is about buying things in Beijing's famous malls or streets like the place in Beijing 'Wangfujin'. Students are not familiar with names of the malls, streets and some cultural backgrounds within the names of the malls or roads, for example the Qianmen street which a famous street and with some culture and history behind it which needs some explanation, students were worried and complaining that the time of the classes is not enough to have enough knowledge about some examples in the books, given that everything from the books have Chinese settings, and they end up losing the understanding of the story.

\subsection{Cultural Differences}

\subsubsection{Greetings}

The cultural differences between Chinese people and Zimbabwean people is one of the many factors affecting the growth of Chinese language in Zimbabwe. In the textbooks which are used, students are usually taught that to greet in Chinese you say "ni hao !" and you reply " wo hen hao" ,or sometimes you can say " ni shenti hao ma?" and you have to reply as "wo shenti hen hao" which means I am fine. Although this is correct Chinese but it has some explanation which have some cultural connotation and can only best be explained when you have to include the culture behind it. For example "ni shenti hao ma" this phrase is a greeting in Chinese, the Chinese people don't usually use it. In Chinese culture usually you can ask "ni shenti hao ma?" to elderly people asking about their health and it's a formal greeting which if you use between friends, Chinese people will think it's strange. To Zimbabwean students, this is what is in the textbooks and that's what they learn. The teachers in Zimbabwe are not aware of the importance of cultural awareness and they end up leaving students learning what is in the textbooks but it doesn't help very much as it is not used in the right context.

When Chinese people are greeting each other usually they use questions. Sometimes for foreigners the questions maybe strange, but in Chinese it's just a greeting which needs a little exposure to the Chinese culture for the Zimbabwean students for them to fully understand the meaning of the greeting of that type. Chinese people can ask questions like 'where are you going?' 'Have you eaten' 'do you have a girlfriend/boyfriend?' 'How old are you?' To Chinese people these are just greetings, but to Zimbabweans most people like privacy and this thing of asking a lot of questions is a strange thing which brings a lot of embarrassment or even anger. Interviewee 1 once went to Chinese to study Chinese at 
Renmin University of China during the international summer school, said she felt embarrassed with a lot of questions which her language partner was asking. In Zimbabwe privacy is important. It's important for the language teachers to explain these things to students so that when they come in contact with the Chinese people they won't be in shock.

\subsubsection{Kinship}

It is important to understand how the Chinese and Zimbabweans call their relatives. In Zimbabwe they don't usually distinguish the relations between people as the Chinese people do. In China they pay much attention and there is a great distinction between relatives, for example those from the maternal side and those from the paternal side. In Zimbabwean culture, they call grandmother to the father's mother which is called 'gogo/mbuya' and the same to the mother's mother, and aunt they just say aunt without distinction. In Chinese its different, you have to understand which side is the person from, for example father's mother is called 'nainai' and mother's mother is called 'waipo' these words when learning in Zimbabwe, students will sometimes be confused, as we did research most students just refer to grandmother as 'nainai' whether from mothers' side or fathers' side because they learnt that word first and because of this ,the growth of Chinese language can be affected as words are used not in the right way.

The difference in culture between Zimbabwe and China is a complex issue that needs a lot of attention if Chinese language is going to improve in Zimbabwe. This paper just researched on some of the issues affecting the growth of Chinese language in Zimbabwe as they are affected by cultural differences between the two countries. A deep research needs to be done in future to address how cultural differences are affecting the growth of Chinese language in Zimbabwe. As cultures are different a lot of differences between can be seen between Zimbabweans and Chinese people, for example how to offer apologies, how to say good bye, how to offer gratitude greetings and so on. In Chinese as we have seen above, greetings are sometimes questions to show concern, intimacy and tend to ask peoples privacies, if these things students don't learn them in class or if they are not aware of these issues, when they come in contact with the native speakers of the target a lot of misunderstandings will be brought.

\section{Conclusion and Suggestions}

As we have noted above language and culture are inseparable and during language teaching, the teacher also needs to understand the culture of the target language and when teaching have to engage the culture part in the class. The behavior of the students is somehow and mostly affected by the culture of the target language and their own culture. According to Li Sun (2013) "communication is a process, and it is not enough for the leaners to simply grasp the knowledge for language forms, grammar and function...leaners must be able to use the language to negotiate meaning in communication, and be able to use the language in appropriate context". This entails how culture learning is important when learning a second language and that teachers and students of the second language need to find and develop new frameworks which will accommodate and develop the learning of Chinese as a second language.

Shen Chen in a bid to improve the learning a second language proposed that foreign language learners need to develop what he calls culture creativity, the practice of this includes students encountering new knowledge, and being exposed to new cultural experiences which should be related to what is already known and experience. In this proposal he tries to link knowledge and ability throughout the learning process. Students in Zimbabwe know a lot of words and grammar but they lack the ability to use the language properly, when they communicate with native speakers of the Chinese language they make a lot of mistakes and a lot of misunderstandings are created. Yin (2009:75), there are various cultural features in foreign language teaching and learning, which he says constitutes cultural barriers in learning a foreign language and using it in communication, particularly in communication with native speakers. Arabski, J, and Wojtaszek (2011) emphasized the role of socio-cultural context in language learning.

The paper although it doesn't give a best approach to how culture should be taught in second language learning but it suggested several ways including the revise of the textbooks being used, teaching of Chinese culture in language classes, raising the importance of cultural awareness in second language teaching amongst other suggestions. It's a difficult and effort demanding job to actually find the best way to foster culture learning in the learning and teaching Chinese as a second language .This paper alone cannot address all the issues but suggests that more researches should be done in future on how Chinese culture is affecting the growth of Chinese language teaching and learning.

\section{References}

[1] Arabski, J, and Wojtaszek, A. (eds.) (2011) Aspects of Culture in Second Language Acquisition and Foreign Language Learning (Second Language Learning and Teaching). London: Springer.

[2] Byram, M. (1997a) Teaching and Assessing Intercultural Communicative Competence. Clevedon: Multiangual Matters

[3] Byram, M. (1997b) 'Cultural awareness' as vocabulary learning. Language Learning Journal, 16(1), 51-57

[4] Byram, M. (1997c) Cultural Studies and foreign language teaching .In S.

[5] Bassnett (ed.) Studying British Cultures. London: Routledge, 53-64

[6] Hu Zhuanglin, Liu Runqing\& Li Yanfu. (1988).Linguistics: A Course Book. Beijing: Beijing University Press.

[7] Liu Xun (2013) Chinese as a Second language. Beijing Language and Culture University Press. Beijing China. 
[8] The People's Daily (2006) Wanted: Four million Chinese teachers for students. Available at http://english.peopledaily.com.cn/200605/23eng20060523 26 7727.html < accessd on 28/11/14>

[9] Xiao Geng, (2010). Cultural Differences Influence on Language.vol 2.no 2 .www.ccsenet.org/res.
[10] Yin, Y.J (2009) On the Cultures in Foreign Language Teaching and Learning. Canadian Social Science, 5(2), 74-78.

[11] Zhang Chun (2014), China-Zimbabwe Relations: A Model of China- Africa Relations? Vol 205 